\title{
University-Industry Partnership for Global Education: Implementing and Integrating an Engineering International Internship into the Engineering Cur- riculum
}

\section{Mrs. Maria Claudia Alves, Texas A\&M University}

Maria Claudia Alves Baudier Director for Engineering International Programs at Texas A\&M University

Ms. Maria C. Alves is the Director for Engineering International Programs at Texas A\&M University. She has been in this position since July 2012. In this position she is responsible for internationalizing the research and education activities of the Dwight Look College of Engineering. Under her leadership the college has increased the number of students studying abroad, established new models of study abroad including co-op and research abroad and established meaningful connection for research and attraction of funded international graduate students. Maria started working at Texas A\&M in 2005 as Assistant Director for Latin American Programs and in 2009 she was promoted to Program Manager for South America in the same office. During her time at the Office for Latin America Programs she created, managed and developed projects to enhance the presence of Texas A\&M University in Latin American and to support in the internationalization of the education, research, and outreach projects of the university. She was charged with the development and implementation of a strategic plan for Texas A\&M in South America. While at the Office for Latin America Programs, Maria was also responsible for the opening of the Soltis Center in Costa Rica. Maria speaks three languages fluently (Spanish, Portuguese and English). Maria completed her undergraduate studies at Lynn University in Florida, where she graduated with honors in Business Administration in 2002. She was part of the tennis team and was the team captain for two years, including the year the team was NCAA National Champion in 2001. She is a December 2003 graduate of the MS-Marketing program at Texas A\&M University. And in the Fall of 2009, Maria started the PhD program in Higher Education Administration and is expected to conclude the program in 2015. 


\section{University-Industry Partnership for Global Education: Implementing and Integrating an Engineering International Internship into the Engineering Curriculum}

Introduction

Engineering organizations, Fortunes 500 companies and the Carnegie Foundation, to name a few, agree with the statement that engineers of the 21st century will be part of a globally connected industry. Consequently "engineering colleges must develop strategies that provide global perspectives and international experiences to help their graduates excel in their future work environment" ${ }^{\text {[1] }}$. Despite this need, only few students are able to or willing to have a study abroad experience. The 2013 Open Doors report from the Institute for International Education shows that nationally only 3.9\% of engineering students studied abroad during their undergraduate career ${ }^{[2]}$. In addition, despite the growing awareness of the benefits of study abroad by students, the challenges preventing students from studying abroad are numerous and complex ${ }^{[2]}$. According to the IIE Generation Study Abroad White Paper Series, the primary challenges for many U.S. students can be grouped into to three overarching categories: cost, curriculum and culture ${ }^{[2]}$.

This paper contributes to the body of knowledge of global education in two ways: First, by describing how a university-industry partnership can support the creation of a new study abroad program and how it can be implemented and integrated into the engineering curriculum of a large college of engineering and therefore providing ways for engineering students to have international experiences. And second, by detailing how this industry-university partnership addresses the primary challenges of cost, curriculum and culture for students to study abroad.

The purpose of this paper is to present the conceptual and operational model of this international internship program detailing the recruitment efforts, student application and selection process, and the implementation of the internship. This paper also describes how the new program was integrated into the curriculum, the challenges faced in that process and how the effort of the university addressed the primary challenges for students to study abroad. Strategies included demonstrating the value industry places on global competencies, preparation of students before the internship and mentorship during the time abroad.

Educators must prepare today's students to succeed in the global economy. This paper provides details on one program which addresses student perceived challenges to study abroad and exemplifies a successful industry-university collaboration to foster the development of global competencies.

\section{Literature Review}

Most of the growth potential for United States businesses will come from overseas markets ${ }^{[2]}$. As stated in the IIE white paperseries "What will it take to double study abroad" from IIE's Generation Study Abroad Think Tank "the rising middle class in developing markets around the world is changing the dynamics of global commerce, and 95 percent of consumers now live outside the United States" ${ }^{[2]}$. Besides opportunities, globalization also poses challenges for 
American companies with some of its greater competition being from foreign-owned companies ${ }^{[2]}$. To face and overcome these challenges, future leaders must be prepared to work effectively in our interconnected world ${ }^{[2]}$. Study abroad program can be an important tool in developing the global mindset needed to succeed in the years to come. As indicated in the IIE white paper series "What will it take to double study abroad” from IIE's Generation Study Abroad Think Tank: Studying in another country opens students' eyes to a new way of thinking about the world, introducing a more informed approach to problem-solving in cross-cultural contexts ${ }^{[2]}$.

There is consent among international educators in the need to do more to prepare today's students to succeed in the global economy ${ }^{[2]}$. Study abroad should be consirered basic training for the 21st century ${ }^{[2]}$ as knowing how to work effectively with people from other countries and cultures are essential skills for all careers, including engineering. Even though studying abroad positively impact students to succeed in this global economy, there is still a large portion of our students who will not or cannot take advantage of this important education opportunity. Research has shown that there are three main reasons preventing United Stated students from studying abroad: cost, curriculum and culture ${ }^{[2]}$. The report written by the Generation Study Abroad Think Tank in May 2014 called what will it take to double study abroad? Describes those three major obstacles, which I added below. Understanding those obstacles will help create programs that overcome them.

"Cost: According to research conducted for A Student Guide to Study Abroad (published by IIE, September 2013), cost was cited as the number one reason students don't go abroad. [...] The cost of studying abroad varies greatly depending on the type and location of the program, the length of stay and whether the program is administered through a university or an outside program. While the overall cost of studying abroad often exceeds that of studying on the home campus-which may lead students to consider it unaffordable-it is a mistake to assume that is the case or that the margin of difference is prohibitively large. Some study abroad programs can actually be less expensive than tuition and fees for the equivalent amount of time on home campus. [...]. The issue of cost, therefore, is twofold: the actual cost of a program and the perception that it is too expensive. Both issues need to be addressed. More scholarships and sponsored sources of funding, as well as a greater awareness of funding options, would very likely encourage and enable more students to go abroad. Higher education institutions also need to continue working to provide less expensive options and more financial assistance, or allow students to take advantage of other cost-effective options." [2]

"Curriculum: Study abroad is not currently considered an essential component of an undergraduate experience by many students, families and educators. In fact, it is often considered an "add-on" and not integrated within the curriculum. Whether or not credits earned overseas will transfer, particularly for certain majors (most notably the STEM fields), creates concern and inhibits many students from studying abroad. Colleges and universities vary widely in how they address credit and grade transfers, as well as how they integrate international experiences into the curriculum. Ideally, it should be integrated within a student's overall undergraduate experience for maximum benefit. To do so, however, takes careful consideration and planning on the student's part and clarity of guidelines and flexibility on the part of the institution. The role of faculty in 
addressing curriculum considerations is critical and plays a significant role in students' academic decisions and perceptions of going abroad. Supportive faculty or department chairs who allow core coursework to be completed abroad help break down the perceived credit barrier. [...]. Barriers to integrating study abroad into the curriculum also affect how well a student is prepared for and can adapt readily to both the crosscultural experience and a new and challenging academic system. If the students are not properly prepared, either one or a combination of the two can catch a student off-guard, leading to poor grades, low comprehension and frustration. This situation can then spur the notion that studying abroad will be detrimental to a student's GPA, or put students behind their classmates due to an inability to grasp key concepts (this is particularly prevalent where students are taking courses in a second language). Faculty and administrators must continue to work closely together to address the issues related to curriculum requirements and credit transfer in order to make it possible for students in all fields to study abroad." [2]

"Culture: Cultural barriers to study abroad are more broad based and pervasive, and cannot be changed by educational leadership alone. [...] In order to make study abroad an essential part of what it means to be educated, we will need to change student and family expectations from a much younger age; provide diverse role models for successful study abroad experiences; address issues of race and ethnicity and increase students' level of comfort with cultures other than their own; demonstrate that employers value the international skills and experience; and enlist teachers, alumni and young professionals in sharing their insight into the value of a global view with high school and college students” ${ }^{[2]}$.

Under culture the report lists eight subcategories that need to be addressed in order to have a culture where study abroad is part of the essential education. Those subcategories are: worldview without an international dimension; influencers; misperceptions; student and family expectations; insufficient preparation; lack of diverse role models; understanding of the role of international experience in different disciplines; narrow definition of study abroad ${ }^{[2]}$.

To prepare our students for the global job market and to increase the number of engineering students studying abroad, new and sustainable models of study abroad programs need to be developed. Internships and other short-term study abroad programs can provide cultural immersion within the context students' career interests ${ }^{[3]}$, which can help them articulate the relevance of the experience abroad to the potential employers. According to studies cited by Gates (2014) and included in the references of this paper - Gardner, Steglitz, \& Gross, 2009; Hart Research Associates, 2013; National Association of Colleges and Employers (NACE), 2013; Trooboff, Vande Berg, \& Rayman, 2007/2008 - international experience can make students more attractive candidates for hiring when students are able to articulate how that experience related to their career or future job ${ }^{[3]}$. In addition according to Gates' (2014) student survey, students also see international internship as valuable experiences ${ }^{[3]}$. Furthermore on her study, Gates (2014) identified other important educational and developmental outcomes for these students, including: experiencing the complexity of issues in ways that cannot be taught in a classroom; learning firsthand about social and economic issues in another culture; and finding an increased sense of self-confidence in themselves as a contributor to a project ${ }^{[3]}$. 
Internship Implementation

Participants in the Generation Study Abroad Think Tank brainstormed many ideas and solutions for increasing or "doubling” the numbers of students studying abroad. Those ideas are summarized below and can guide higher education institutions in their internationalization efforts:

1. Redefine, rebrand and modernize the concept of "study abroad."

2. Engage accrediting bodies to have them include global competencies in their rubrics.

3. Reframe the problem as a K-20 issue and address it at all levels.

4. Use research strategically and more practically.

5. Engage the foreign language learning community as an ally and partner.

6. Secure buy-in from the top of institutions in order to mandate change.

7. Fix the broken systems on campuses that unnecessarily hinder study abroad.

8. Provide incentives to all stakeholders who stand to gain by expanding study abroad.

9. Develop creative partnerships with the private sector to raise funds, increase public awareness and link study abroad to careers.

10. Make global locally relevant to parents, communities and businesses.

11. Don't be afraid to consider radical ideas. ${ }^{2]}$

The international Internship Program being described in this paper falls under the idea listed as number nine "Develop creative partnerships with the private sector to raise funds, increase public awareness and link study abroad to careers”. Tenaris, the leading supplier of pipes and related services for the energy industry, that was the partner for this program, has an aggressive growth plan in the Central Texas area where the Dwight Look College of Engineering (Look College) of Texas A\&M University is located. As is right now, Tenaris already hires several students of the Look College. However, due to the lack of presence or awareness of this company in the mind of students, some of the best students choose to go to other companies when selecting their internship and employment place. This was the first incentive for Tenaris to approach the Look College for a partnership - to increase their presence in the mind of students. Tenaris is also an international company with its headquarters being located in Luxembourg and with operations and markets all over the world. With that, Tenaris would like to hire students that have a global curiosity, a global mindset and are prepared to work with diverse and international colleagues, supervisors and employees even if they are based in the United States. Besides the presence in the college's career fair and the regular internship program, Tenaris partnered with the college to create a special program - The Tenaris/Texas A\&M Engineering Summer International Internship.

The international internship, from Tenaris’ perspective, would allow it to recruit the best students by providing a unique opportunity to those students. It would also allow the company to prepare students to have a global mind set and to be immersed in other cultures and in the global culture of Tenaris, and at the same time evaluate students' performance in the international environment before hiring them. Last but not least, It would increase the presence of the company in the mind of the students by providing this "cool” program, a once in a life time opportunity and therefore showing what the company is about. 
From the Look College's perspective, this would be a new opportunity for students to go abroad, an abroad program completely related to their field of study, and a program that help address three of the main challenges in sending the students abroad for education experience: cost, curriculum and culture. Cost was addressed by the sponsorship of the company that paid for the internship and all of the travel related cost including, visa fees, airfare, housing, local transportation and meals. Curriculum was addressed by the internship being related to their field of study, and by having students register for a 1 credit of ENGR 484 (International Internship) under the supervision of the co-op faculty of the department. With this being true engineering internship with an intensive international emersion; this class could be used as a technical elective and an "international, culture and diversity requirement".

In regards to culture the program addressed two points in this one topic. First, it addressed the lack of value students see in going abroad, which was overcome by having a company making the statement that this is so important in today's job market that they created this program in partnership with the college and funded - they put their money where their mouth is. The second point related to culture that was addressed in the program is the lack of preparedness of the students for going to other cultures and the support during the program. The Look College and Tenaris organized orientation sessions to prepare students for this experience. In addition, Tenaris assigned a mentor for each student at the destination country. The mentor was not only an engineering job mentor, but also a culture mentor. The mentor took the students around the country the students were doing their internship and helped with the culture emersion and culture shock.

\section{Recruiting and Selection}

The recruiting was done jointly between Tenaris and the college. Tenaris used the same application site they use for their job and internship applications. The Look College created a website to promote and explain the program and added the application link created by Tenaris in the website. The Look College and Tenaris organized several events to promote the new program including: joint information session with pizza on campus, having an engineer from the company give a presentation in the honors class, and participation of the company in the career fair events of the college and the university. The opportunity for the internship was shared with the students via the college list serve as well as by the academic advisors of the engineering departments, which reinforced the curriculum aspect of this opportunity.

The selection was done $100 \%$ by Tenaris and had several phases. First students had to pass a numerical reasoning test. Tenaris only looked at CVs and applications of the students who passed the test. Tenaris selected the students for an on-campus interview. And students who passed the campus interview were invited for the second and last round of interviews in the company site with top level engineers and managers. This ensured that Tenaris was selecting the students who would fit the profile of the company not only for a successful internship but for consideration for future employment. Having Tenaris take care of the selection was an important aspect of the success of the program because the company selected students with the skills needed for the company and for the projects the company had for the summer internship. 


\section{Pre-departure Orientation}

There were two pre-departure on campus orientations and one week-long orientation in the company site. The first orientation on campus was done in the evening and Tenaris provided dinner. Students met all 12 participants and Tenais gave a presentation on the company history, products, mission and future goals. Tenaris also presented the program, objectives and expectations. The college participated in this orientation as well explaining the academic side of the program, informing students that this internship was for credit and integrated into credits needed in their degree plan and the Engineering International Certificate.

The second on campus orientation was also in the evening with dinner being served. At that orientation students were informed of the country they would have their internship. The selection between the student and the location was done by Tenaris based on the project needs of the location and the expertise of the student. During this second orientation the company presented the history of each of the internship location within the company, for example, Argentina was where the company started, Mexico is the largest plant of Tenaris and Romania was a recent acquisition. Tenaris also explained the relevance of that location for the company and gave basic information about the country and culture they would be immersed in. Other program details were shared during this time, such as the departure and return date and information about the week training in the company.

The week training at Tenaris in Houston took place a week before the departure to the internship company. Students were requested to travel to the Houston ready to travel to their internship countries. During the week training students got more familiar with the company's products, goals and culture. Students were also presented with their summer internship project and had skype meetings with the branch of Tenaris that would host them and met with their individual mentor. On the last day of the training students received a global competitiveness training to prepare them for culture shock and help them be ready for the experience.

\section{Internship Implementation}

On the university side students registered for a 1 credit of ENGR484 International Internship under the supervision of the co-op faculty members. Students were expected to write a final internship report to receive the grade. Students also registered with the study abroad programs and bought the university international insurance and were added to the list of students abroad to the respective countries. The class student registered for counted as a technical elective and ICD (International Culture and Diversity) credit.

Tenaris took care of the students' visa, housing on the host country, local transportation, student stipend and payment. Students were paid the equivalent to what the students who did their internship in the United States made. The students were integrated in the internship program of the local country and with that were fully emerged in the country and company culture.

There were 12 students selected for the international internship on Summer 2014. Four students were assigned to Argentina, four students to Mexico and four to Romania. Each student had a country mentor, an internship group and their own internship project that was assigned to them 
based on their skills, interest and background. There was no language requirement. All of the work and interaction with local company employees was done in English. This helped student feel confortable and confident that they could deliver and do a good job. However, students also got exposed to the local language as in the cities they were most people would speak just the local language.

On the second week of the fall semester, after the students were back in the United Stated, the Look College organized an evening event on campus with Tenaris where the leadership from the college and the company participated. The event was open to all of the students in the college of engineering. The students who participated in the program gave a group presentation about their cultural experience and an individual presentation about their individual project.

\section{Program Outcome}

Students started their internship on June $9^{\text {th }}$, 2014. Tenaris contacted students and their supervisors every two weeks to follow up on the development of the program and of the students. Two of the feedback shared by the company with the researcher were very positive and are summarized below.

June 18th student and company feedback:

Romania: Students are over their jet lag and they are taking full advantage of exploring and learning as much as they can this summer. Their country mentors' have played a huge role in their experience so far. They are all getting along great and have made plans all summer to show them the country and area. This weekend the country mentors are taking them to a Music Festival with 50 or so bands. In the coming weekends, they already have plans to visit Budapest and Dracula's castle. One of the students has had some nosebleeds (climate change), but is feeling great now and was very well taken care of. Projects are going well and they are learning lots!

Argentina: Students seem to be adjusting well! They all raved about the international internship program manager showing them around Buenos Aires (the second week of the interns in Argentina coincided with the program manager business trip to Buenos Aires, where she is from, and she took that opportunity to show them around). Projects are challenging and off to a nice start. They do not mind the food at the hotel because it is so cheap. This weekend they are going to visit Iguazu Falls and taking advantage of a 3 day weekend (Flag Day in Argentina). They are convinced they will be fluent in "Spanglish" by the time they return.

Mexico: There has been some crazy weather in Mexico and the area has even had some flooding. They are living in the same hotel as the Mexican interns and they have really appreciated their help getting around and translating. Yesterday everything shut down from 2-4pm for the Mexico vs. Brazil game (the internship coincided with the 2014 World Cup). What a neat experience for them! They described it as being on a roller coaster with lots of yelling, excitement and pure terror when Brazil would score. They have plans to visit Xalapa, Puebla, and the Mayan Ruins over the next few weekends. 
June 30th student and company feedback:

Romania: All 4 projects are going well and keeping them very busy. They traveled to 3 different cities this past weekend so were still a little tired today.

Argentina: They are all enjoying their projects and learning a lot. Two weekends ago they visited the waterfalls so this weekend they relaxed and stayed in Campana. They are very excited that many of the Global Trainees will be arriving later this week for their training. They were requesting for the Americans to bring some snacks they are missing!

Mexico: Two weekends ago they visited Xalapa with some of the Mexican interns they have befriended. This past weekend they stayed in the Veracruz area to explore more of the sites there. They said: sad is an understatement of how the Mexicans handled the loss to The Netherlands! Projects are all going well!

Romania student blog on last day: "This experience was amazing on many accounts. The experience would have been nothing without our friends. All the adventures we had, whether in a different city, in the office, or around Zalau: they were all worthwhile. Playing pool, going to the town's only credible pub, eating bad fast food, laughing in the canteen, going to Kaufland, learning to drive a manual, playing tennis and basketball, watching movies, going out for a beer, discovering Budapest, Tibi's Cabin, Brasov, Sibiu, Sinaia, Cluj, BBQs, Saladina, Giorgios. All of their worth was because of the people we shared those times with, our friends. When I think of Romania, it's not the food or scenery that comes to mind. Romania to me is Mircea Stef Irina Nana Alex Alin Alexandra Lucian Zoli Mihai Vlad Gaby Sorin Morent Tibi Victor Florin Cristina Gabriela Liviu Georgiana Dana Lucia Danny Florin Daniel Maria and more. I will miss them all in different ways, and have said or will be saying my goodbyes accordingly to each"

From those reports, the student's blogs and their final presentations it is noticeable how rich professionally and personally this experience was for the students who participated. They made friends from different parts of the world and learned how to interact with them, experienced different food, visited unique cities and have been expected to perform professionally in a foreign environment. One crucial aspect for their fast adaptation to the new environment, and positive experience while abroad was their country mentor. This was very clear from the conversation with students, their blogs and the video the company made of this program. The college has now adapted the concept of the country mentor to other program that it has in sending students abroad or hosting students from abroad. Having more feedback from the company on students'performance, getting the complete set of students report and interviewing the students will allow for a richer report on this program.

From the company's perspective the outcome was positive. The program will take place again for summer 2015 and fourteen students will be participating this time. So the company has seen positive results and determined it is worth the investment on the program again with a small increase on the number of students. Out of the 12 students who participated in the program, one student have accepted full time position with Tenaris, and three have accepted a domestic internship with Tenaris, as they have yet, not graduated. Three students were not extended an 
offer for full time job, and five denied a full time job or internship. This is important to mention because companies will be looking for a return on their investment. While one of the returns is the increased brand presence in the college and the mind of students, which at this point is hard to quantify, the recruiting number is another important and very direct measure that can be listed right now. Both Tenaris and the Look College are getting ready for the 2015 program and looking into better ways to assess the program and to have a better transition into full time jobs with the company.

\section{Revisions and Improvements Needed}

For the program that will take place on Summer 2015, one thing that was done differently is that the adverting and recruiting started in the Fall 2014 rather than in the Spring 2015 as in the previous year. This allowed the company to organize many more recruiting events and to have a larger/better pool of candidates to choose from. There were two events jointly organized by the Look College and Tenaris in the Spring 2015, one had 70 attendees and the other 150 attendees, which shows the snowballing effect of the word about the company and the program getting around. How the program is integrated into the curriculum of the students is an area that the college is working with academic advisors to improve. However, since the program takes place during the summer it does not interfere with other academic activities. Other than that the program will follow the same format.

\section{Conclusion}

The international internship created in partnership with Tenaris added value to the company, the college and the students'education. Following the ideas presented by Generation Study Abroad Think Tank this was a creative partnership with the private sector to raise funds, increase public awareness and link study abroad to careers. The program was created in such a way that addressed the three main barriers for students to study abroad: cost, curriculum and culture. As the company covers all the costs associated with the program, the cost barrier is well covered and overcome by the program. Curriculum integration and culture are two aspects with growth potential.

By presenting the conceptual and operational model describing and detailing the implementation and outcome of this Tenaris-Texas A\&M Engineering international internship program, the author hopes to help other institutions in creating effective international internships as well as establishing a model that can be implemented in partnership with other companies at the Look College. Thoughts on future research related to this program is to determine the global competency learning of the students and compare this program with other study abroad programs currently taking place in the college. More information will be gathered for the program that is being implemented for summer 2015.

\section{Acknowledgements}

With the conclusion of this paper it is important to acknowledge the key people who made this program possible. For their vision and determination in creating new programs that will change engineering education, and for sponsoring the Tenaris-Texas A\&M Enginering International 
Internship Program on Summer 2014 and their commitment to continue in 2015: German Cura, President of Tenaris North America; Paola Mazzoleni, Human Resources Director at Tenaris, Maria Laura Guolo, Human Resources Development Manager at Tenaris, and Ashley Marcantel, Campus Recruitment at Tenaris

\section{Bibliography}

This paper has been accepted in the International Division of the $122^{\text {nd }}$ ASEE Annual Conference \& Exposition (June 14-17, 2015 Seattle WA - Paper ID \#12725). It will be presented in the techincal session and will be published with the proceedings of the conference.

[1] C. C. Borri, E. E. Guberti and J. J. Melsa, "International dimension in engineering education," European Journal Of Engineering Education,, vol. 32, no. 6, pp. 627-637. doi:10.1080/03043790701520586, 2007.

[2] Institute of International Education, "IIE Generation Study Abroad White Paper Series," May 2014. [Online]. Available: file:///C:/Users/mariaalves/Downloads/GSA-Outcomes-Green-Paper.pdf. [Accessed 16 October 2014].

[3] L. Gates, "The Impact of International Internships and Short-Term Immersion," NEW DIRECTIONS FOR STUDENT SERVICES, vol. 146, pp. Published online in Wiley Online Library (wileyonlinelibrary.com) - DOI: 10.1002/ss.20088, 2014.

[4] B. K. Jesiek, Y. Shen and Y. Haller, "Cross-Cultural Competence: A Comparative Assessment of Engineering Students," International Journal of Engineering Education , pp. Vol. 28, No. 1, pp. 144-155, 2010.

[5] F. Najafi, D. Jet and N. Safai, "A global model for higher educational institutions to increase the enrollment of minority and international students," in ASEE Annual Conference and Exposition, Pittsburgh, PA, 2008.

[6] C. D. W. Goodwin and M. Nacht, " Absence of decision: Foreign students in American colleges and universities: A report on policy formation and the lack thereof," Institute of International Education, New York, 1983.

Other References

Gardner, P., Steglitz, I., \& Gross, L. (2009). Translating study abroad experiences for workplace competencies. Peer Review, 11(4), 19-22

Hart Research Associates. (2013). It takes more than a major: Employer priorities for college learning and student success. Liberal Education, 99(2), 22-29.

National Association of Colleges and Employers (NACE). (2013). Job outlook 2013, Spring Update. Retrieved from http://www.naceweb.org/Research/Job Outlook/Job Outlook.aspx

Trooboff, S., Vande Berg, M., \& Rayman, J. (2007/2008). Employer attitudes toward study abroad. Frontiers: The Interdisciplinary Journal of Study Abroad, XV, 17-34. 